\title{
The Correlation and Appropriateness Between Affect Valence of Consumer and Design Feature: Preliminary Evidence from an Event-Related Potentials Investigation
}

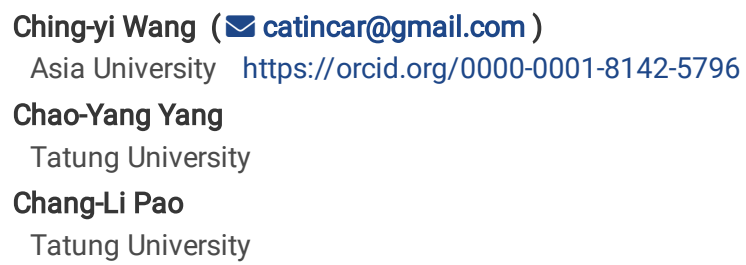




\section{Abstract}

Background: Consumer requests in selecting products in recent years have been transformed from the functional practicability to affect request. The affect factors have a great influence on the decision-making process of consumers when purchasing products. This study takes the watch as the research example, discusses the effects and correlation of its design feature to the emotions; the results are supplemented by the objective reflection of measuring brain waves.

Results: Brain wave readings of 16 interviewees with designing backgrounds are recorded, as well as the reflection brain zone and amplitude of the LPC component with the Event-related Potentials (ERPs). The research verified that the shape, percentage, patterns and colors will affect the emotional reactions of consumers' brains.

Conclusions: The research results can promote an ERP measurement tool to detect relevant consumer topics or design research. In addition, the combination and matching of different design elements can also serve as the designing parameters for the innovation of a digit model, as well as raise the systematic emotion design in accordance with the design factors that effectively affect consumers' emotions.

\section{Introduction}

The design and development targets of designers related to their products have been progressively centralized by the consumers, leading to an increased understanding of consumers' preferred design features of products. However, the products are experiencing decreasing changes with the respect of technical specifications, and the differences in product functions are gradually reduced under the mutual intensive competition of enterprises. The growing focus of consumers regarding the quality of products means that consumers have transformed from seeking satisfaction according to the functions of products to the psychic satisfaction of product image. Purchasing products is no longer a simple function, but some consumer goods enable purchasers to generate emotional fluctuations. Therefore, as far as the consumer is concerned, the product is not only just a tool, but also an emotional connection; the design appearance is also an emotion provoking image (Jordan, 1998). In order to understand consumers' preference for products and their designing methods we need an historical review. In the past, the designers mainly relied on individuals' thoughts to design the shape of products, but they did not comply with the total demands of consumers in the market (Rajapakse et al., 2009). Currently, designers usually create one product for inspiring the visual sense of beauty for potential users through the design elements (e.g. linear, surface and color) and aesthetic principles (e.g. uniformity, contrast ratio, balance and proportion) (Coates, 2003). Some studies prove that the emotions play the important decisive role in purchase decisions (Steenkamp, 2005). Moreover, a sense of beauty featured in the products purchased by consumers also plays a key role in purchase decisions (Hoyer et al., 2012). In the past, the questionnaire measurement method based on the adjectival phrase was mostly applied when discussing the emotional reaction to the products/services of users or consumers (Likert scale). However, the questionnaire results may be affected by the subjective consciousness, e.g. whether the interviewees understand the original meaning of questions, and whether the expression ability of interviewees results in differences related to the content of questionnaires (Wang \& Chung, 2017; Jenkins et al., 2009; Lin et al., 2011a, 2011b). Physiological measurement through the heart rate (HR), galvanic skin response (GSR) and electroencephalography (EEG), etc., methods are able to acquire the information. EEG reads the reactions of brain to the information brought by the stimulus, which is relating to the physical activities e.g. identification, comparison, judgment, memory, decision-making, etc. The physiological and emotional reactions have mutual relationships with respect to vision. The brain waves are regarded as a measurement tool for deciding the visual and physical status. In the past, studies identified that the physical and cognitive activities would generate differences in brain waves. This process was able to observe the positive and negative emotional motivation in EEG in seeking to understand the emotional differences (Carretié et al., 2003; Montoya \& Sitges, 2006). Therefore, brain waves are appropriate for discussing the reactions aroused by emotional stimulants. This study will objectively examine the relationship between the design elements and emotional reactions to products through the emotion dimension scale and ERP test.

\subsection{Emotion dimension measurement}

In the emotion dimension scale, valence and arousal are the most common measuring dimensions (Russell, 2003). Valence refers to the degree of happiness. Arousal describes the intensive emotions from calmness to excitement (Russell, 1981, 2003; Lang et al., 2001). Figure 1 displays that the core emotion experience is the coordinate axis comprising the two dimensions of horizontal and vertical, with two dimensions of valence and arousal for judgment and explanation. The horizontal axis is affect valence, which is the degree of negative and positive emotion composed of the Pleasant of positive valence to the Unpleasant of negative valence. The vertical axis is the degree of emotion arousal comprised of the sleepiness aroused from low to the excitement aroused from high, as well as the interactive correlation between the various emotions. Past research indicated that the valence and arousal not only had the emotion memory and different nerves, but also generated some different effects (Mickley, Steinmetz \& Kensinger, 2009). Identifying the emotions has the apparent practicality and importance to understand consumer behavior. The effects of emotion handling with the corresponding respect of angle and curve shapes have been supported by the evidence of neurosciences, and highlighted the effects of emotions in the multiple sensory perception handling and shape perception ((Bar \& Neta, 2007; Blazhenkova \& Melisa, 2017; Brown et al., 2011; Drevets \& Raichle, 1998; Palmer et al., 2013; Vuilleumier, 2005). In addition, the subjective valence and arousal class of geometric stimulation are obviously different e.g. the triangle is regarded as the unpleasant and more exciting shape (Armbruster et al., 2014).

Insert Fig. 1 here

\subsection{Relevant research on ERP and emotions}


Currently, visual emotion stimulation has proven to be able to obtain the different components of ERP, including the relevant early-stage perceptional reaction, EPN (early posterior negativity) component arousing attention (Flaisch et al., 2011; Frühholz et al., 2011; Junghofer et al., 2004; Kissler et al., 2007; Herbert et al., 2008; Schacht and Sommer, 2009a; Recio et al., 2011), as well as the LPC (Late Positive Component) (Flaisch et al., 2008, 2011; Herbert et al., 2008; Recio et al., 2011; Schacht \& Sommer, 2009a, 2009b; Schupp et al., 2000, 2004). Therefore, the physiological emotion features may appear in the brain rather than the reaction appearing in the body (Cuthbert et al., 2000). This important reaction information can't be obtained by applying the questionnaire. Observing the changes of brain signals and the main ERP brain components by applying the electroencephalogram is regarded as the reaction of consumer perception (Wang \& Han, 2014). ERP has the feature of high time resolution; it is able to better reflect the time flow of neural activity with ERP as the index. In terms of the research on emotions, ERP proven to be able to detect the obvious effects through emotion stimulation (positive or negative) e.g. advertisements, facial expression, etc. (Dolcos et al., 2002). In addition, Berridge \& Robinson (2003) point out that the left and right sides of the brain simultaneously produce the living reaction when experiencing the pleasant, which indicates a close relation between the emotions and the brain. Moreover, the usage of a high arousal stimulant matches the positive or negative stimulation; low arousal matches neutral simulation images in discussing the amplitude degree of arousal. The research results indicate that high arousal matches positive and negative stimulants with all emotions reflected by the ERP amplitude of different zones in brain (Olofsson et al., 2008). In addition, ERP can observe the correlation of different elements of products to consumers e.g. the property, brand, advertisement of products; as well, it is able to evaluate the different signals through monitoring the brain activities (Hansen et al., 2010).

\subsection{LPC evaluation}

LPC is regarded as the component related to the evaluation significance, which is widely applied to the research on emotions (Hajcak, et al., 2006; Hajcak \& Nieuwenhuis, 2006; Ito et al., 1998). The positive or negative emotions stimulate LPC of 400-800 milliseconds compared with the neutral stimulation (Flaisch et al., 2008). LPC has the feature of Negativity Bias, which will input more attention resources to the images with threatening negative emotions e.g. violation, sensational, blood, anger, fierce animals, etc. In the research on image perception, the factors affecting the time length of attention are based on difficulty (Rayner, 1998; Rayner \& Duffy, 1986), interest or intention (Norton, 1971a, 1971b, 1971c; Yarbus, 1967), as well as curiosity, complexity and incompatibility (Henderson et al., 1999; Loftus \& Mackworth, 1978). Long-time eye fixation usually refers to the multiple physical processes (Rayner, 1998). For example, when the observer is observing the objects in an image, the incompatible objects may attract the long-time fixation of eyes in the scenery natural composition (Henderson et al., 1999; Loftus \& Mackworth, 1978). Olofsson et al. (2008) believes that the amplitude of LPC depends on the volume of the physical resource configuration of subjects. Many studies find that the amplitude of LPC is higher than the positive emotions and neutral emotions (Ito et al., 1998; Kern et al., 2005; Lang et al., 2001; Wood \& Kisley, 2006). Ito et al. (1998) tested the images of positive emotions, no emotions and negative emotions, and identified that the LPC amplitude of the images with negative emotions was the highest, higher for the images with positive emotions and also that there was no LPC reaction for neutral emotions. Luo \& Huang (2006) also obtained the same results, and identified that the stimulant with emotion images would be shorter than the incubation period of neutral images, which indicated that the subjects would prioritize in order to analyze and evaluate the stimulant with emotion value information. During this process, the subjects could seriously consider and manipulate the entire evaluation process, the information could be thoroughly analyzed, and it was able to include more consideration factors related to the experience. Therefore, the analysis evaluation is a controlling and processing process from top to bottom. The subjects can decide to perform more evaluation to certain stimulants and distribute more physical resources in accordance with their own demands and the actual environmental status. Kern et al. (2005) explain that when the information contained in the positive stimulant was not intensive, people would prefer to prioritize to handle the negative information in the situation of limited resources. This preference is the adaptive response for ensuring biological survival (Luo \& Huang, 2006). Because people always easily pay attention to negative information, but have no feelings related to the positive information, when ignoring the positive stimulation, what have been lost the most are the opportunities. But failing to notice the negative stimulation (e.g. predator) may lead to the loss of the instinct of survival. The negative events require shorter time to complete the physical processing of emotion stimulation than the neutral events do, which can provide more physical energy, while saving time to enable the body to act as soon as possible, as well as adapt to the environment in a rapid manner (Lang et al, 2001). In addition, Hamilton \& Fallot (1974) identified that the negative features would obtain more weight compared with the positive features, which indicates that the negative images have more influence than the positive images. However, this result is inconsistent with those of other studies (Schapkin et al., 2000; Delplanque et al., 2004; Herbert et al., 2008), which identified that the pleasant stimulant will reinforce the LPC reaction more than the unpleasant stimulant will, and that the ERP amplitude produced by the positive emotion images is stronger than the negative emotion images (Spreckelmeyer et al., 2006). For example, Jacobsen \& Höfel (2002) discuss the effects of symmetrical and asymmetric geometric figures (e.g. triangle, square and rhombus) in relation to the esthetical quality. The thinking group with evaluation can arouse stronger LPC amplitude than the browsing group can, without thinking in terms of judging the sense of beauty, and both groups can arouse great LPC amplitude when observing the asymmetric images rather than symmetrical images. As a result, we can understand that not all amplitudes aroused by the negative emotions are larger than those of positive emotions; the main reason is that the negative emotions aroused by the unaesthetic images will not somehow be affected in terms of the aesthetic quality of geometric figures.

\subsection{Purpose of the research}

The purpose of this research is to investigate the affecting degree from the design factors of products to the positive-negative emotions of consumers, as well as using ERP to measure their emotional reactions. The test simulation uses the watch as the research example. On the basis of current trends of products, the watch design may have various shapes due to the demands of consumers; as well, the style is developing more to decoration, lightening and thinning, individuation, interestingness, etc. The watch is not only the accessory with respect to decoration, but also displays personal features and taste. Therefore, discussing how the watch combination factors influence the aesthetic attitude of consumers and generate the emotion connections is worthwhile. The above-mentioned studies prove the preferences and reactions of the brain to negative information. Since the negative impression bias of 
products will greatly influence the consumption decision of customers, understanding the consumers' perspectives is essential in this research; studying and evaluating the negative properties of products are required. Since products can only provide the positive property selection for consumers, we cannot know how the negative preferences influence consumers' decisions in a precise and complete manner. This research posits that it is possible to avoid purchase failure caused by the negative emotions of consumers through understanding the negative information of products. The research results can provide the selection criteria for evaluating the negative property of products for the designers or marketers in an appropriate manner, as well as consider how to improve the products, service, or the brand equity.

\section{Method Of Research}

\subsection{Subject}

There were 16 subjects ( 11 males and 5 females; average age $=23.38 ;$ Std $=1.26$ ) with an educational background of college and above in Taiwan and a background of industrial design, in addition to having received professional training on product shape design, so they were able to perform the precise shape image judgment of the products. The subjects have the relevant knowledge of art, which is helpful to the performance of operation demand, especially during the observation test of aesthetic evaluation; the subjects were able to fully apply their aesthetic knowledge to expedite the mechanism of perception and attention (Locher, 1996). This study was reviewed and approved by the Research Ethics Committee National Taiwan University. All participants gave written informed consent in accordance with the Declaration of Helsinki.

\subsection{Sample}

\subsubsection{Card sorting for selecting sample}

During the first stage, the experts will classify and select the representative samples by card sorting, for the second stage questionnaire. Three experts with over six years of experience in product design and watch collection were invited ( 3 males; average age $=45.66$; Std $=5.6$ ) to perform the card sorting of the collected 360 watch photos, select the representative samples, and then produce the basic 3D shape through the drawing software Rhino and rendering software KeyShot 5. The samples eliminated the interfering elements e.g. electronic display, number (consider the glyph), color and complex elements (exterior decoration), sorted into the watch frame and watch surface, as shown in the Fig. 2 and Table 1. The watch frame is composed of the 1:1 and 1:1.5 proportions and $\mathrm{R}$ angle (with $\mathrm{R}$ angle and without $\mathrm{R}$ angle). The watch surface comprised the content (tradition and intelligence), background (white and black) and color (black, white and colors) of the watch surface. 
Table 1

Sample list.

\begin{tabular}{|c|c|c|c|c|c|c|c|c|c|c|}
\hline Type & \multicolumn{2}{|c|}{ Design element } & Type 1 & Type 2 & Type 3 & Type 4 & Type 5 & Type 6 & Type 7 & Type 8 \\
\hline \multirow[t]{5}{*}{ frame } & \multicolumn{2}{|l|}{ shape } & Circle & Ellipse & Square & Rectangle & Triangle & Arc & & \\
\hline & \multirow[t]{2}{*}{ Ratio } & $1: 1$ & Circle & Square & Triangle & & & & & \\
\hline & & $1: 1.5$ & Ellipse & Rectangle & Arc & & & & & \\
\hline & \multirow[t]{2}{*}{ Radius } & Radius & Circle & Ellipse & Square & Rectangle & Triangle & Arc & & \\
\hline & & No radius & Square & Rectangle & Triangle & Arc & & & & \\
\hline \multirow[t]{7}{*}{ surface } & \multicolumn{2}{|l|}{ Pattern } & No depict & $\begin{array}{l}\text { Point } \\
\text { depict }\end{array}$ & $\begin{array}{l}\text { Line } \\
\text { depict }\end{array}$ & $\begin{array}{l}\text { Point and } \\
\text { line depict }\end{array}$ & $\begin{array}{l}\text { Line depict } \\
\text { (Black) }\end{array}$ & Information & $\begin{array}{l}\text { Intelligent } \\
\text { (black } \\
\text { and } \\
\text { white) }\end{array}$ & $\begin{array}{l}\text { Intelligent } \\
\text { (Colorful) }\end{array}$ \\
\hline & \multirow[t]{2}{*}{ Content } & Traditional & No depict & $\begin{array}{l}\text { Point } \\
\text { depict }\end{array}$ & $\begin{array}{l}\text { Line } \\
\text { depict }\end{array}$ & $\begin{array}{l}\text { Point and } \\
\text { line depict }\end{array}$ & Information & & & \\
\hline & & Intelligent & $\begin{array}{l}\text { Intelligent } \\
\text { (black } \\
\text { and } \\
\text { white) }\end{array}$ & $\begin{array}{l}\text { Intelligent } \\
\text { (Colorful) }\end{array}$ & & & & & & \\
\hline & \multirow[t]{2}{*}{ Background } & White & No depict & $\begin{array}{l}\text { Point } \\
\text { depict }\end{array}$ & $\begin{array}{l}\text { Line } \\
\text { depict }\end{array}$ & Information & & & & \\
\hline & & Black & $\begin{array}{l}\text { Point and } \\
\text { line } \\
\text { depict }\end{array}$ & $\begin{array}{l}\text { Line } \\
\text { depict } \\
\text { (black) }\end{array}$ & $\begin{array}{l}\text { Intelligent } \\
\text { (black } \\
\text { and } \\
\text { white) }\end{array}$ & $\begin{array}{l}\text { Intelligent } \\
\text { (colorful) }\end{array}$ & & & & \\
\hline & \multirow[t]{2}{*}{ Color } & $\begin{array}{l}\text { Black and } \\
\text { White }\end{array}$ & No depict & $\begin{array}{l}\text { Point } \\
\text { depict }\end{array}$ & $\begin{array}{l}\text { Line } \\
\text { depict }\end{array}$ & $\begin{array}{l}\text { Point and } \\
\text { line depict }\end{array}$ & $\begin{array}{l}\text { Intelligent } \\
\text { (black and } \\
\text { white) }\end{array}$ & Information & & \\
\hline & & Colorful & $\begin{array}{l}\text { Intelligent } \\
\text { (Colorful) }\end{array}$ & & & & & & & \\
\hline
\end{tabular}

\subsubsection{Questionnaire evaluation}

The second stage focused on the emotions and attitudes of interviewees to the samples by the means of a questionnaire. It applied the semantic differential scale to select the appropriate samples for brain wave testing. This research invited 30 persons ( 15 males, 15 females; average age = 21.33 ; $S t d=1$ ) whose educational background is college and above in Taiwan with a background in industrial design and reception of professional training on product shape design; in addition, they were able to perform the precise image judgment related to the product shape. The semantic differential scale (Russell, 2003) applies the raised concept of core emotion, combined with two dimensional emotion reactions: physiology and psychology to constitute the circuplex model of emotions, while the core emotion experience is the coordinate axis composed of the horizontal and vertical dimensions. According to the theory of information aesthetics, the aesthetic emotions aroused by visual information can serve as the standard for aesthetic evaluation judgments, as well as establish the constitution relation with the visual information (Eysenck, 1968). In addition, 'pleasant' is the important reaction for aesthetic emotion (Fechner, 1876), which indicates that the aesthetic perception can arouse the pleasant emotion reaction. Therefore, this research takes the emotion reaction aroused by the aesthetic factors, and regards the emotion valence (Pleasant vs. Unpleasant) as the scoring standard, in addition to applying a Likert scale of one to five for the evaluation.

In Table 3, according to the questionnaire survey results during the second stage, 30 pictures were selected respectively for the positive high emotion valence and negative low emotion valence as the samples for brain wave test by taking the affect valence as the selection standard. In addition, another 30 colorful scenery pictures (neutral pictures) from the Nencki Affective Picture System (NAPS) were selected as the neutral stimulant (Riegel et al., 2016). There were 90 pictures in total (see Fig. 3) as the samples for the brain wave test. 
Table 3

Group mean LPC amplitudes of the responses to positive, negative, and neuronal conditions that were recorded from 9 electrodes over 9 regions of the scalp: left-anterior (F3), middle-anterior (Fz), right-anterior (F4), left-central (C3), middle-central (Cz), right-central(C4), left-posterior (P3), middle-posterior (Pz), and right-posterior (P4) (standard deviation of the mean in parentheses)

\begin{tabular}{|llllllllll|}
\hline Condition & $\begin{array}{l}\text { left- } \\
\text { anterior }\end{array}$ & $\begin{array}{l}\text { middle- } \\
\text { anterior }\end{array}$ & $\begin{array}{l}\text { right- } \\
\text { anterior }\end{array}$ & $\begin{array}{l}\text { left- } \\
\text { central }\end{array}$ & $\begin{array}{l}\text { middle- } \\
\text { central }\end{array}$ & $\begin{array}{l}\text { right- } \\
\text { central }\end{array}$ & $\begin{array}{l}\text { left- } \\
\text { posterior }\end{array}$ & $\begin{array}{l}\text { middle- } \\
\text { posterior }\end{array}$ & $\begin{array}{l}\text { right- } \\
\text { posterior }\end{array}$ \\
\hline positive & 0.67 & 0.75 & 0.90 & 0.83 & 0.91 & 0.86 & 0.99 & 1.16 & 0.95 \\
\cline { 2 - 10 } & $(2.06)$ & $(2.00)$ & $(2.18)$ & $(1.31)$ & $(1.30)$ & $(1.16)$ & $(0.98)$ & $(0.96)$ & $(0.75)$ \\
\hline negative & 1.49 & 1.60 & 1.62 & 1.61 & 1.68 & 1.59 & 1.65 & 1.88 & 1.67 \\
\cline { 2 - 11 } & $(1.60)$ & $(1.72)$ & $(1.60)$ & $(1.11)$ & $(1.25)$ & $(1.11)$ & $(1.06)$ & $(1.03)$ & $(0.86)$ \\
\hline
\end{tabular}

Table 2

Descriptive statistics for samples of positive high affect valence and negative low affect valence.

Insert Fig. 3 here

\begin{tabular}{|lllll|}
\hline \multicolumn{5}{c|}{ valence. } \\
\hline sample & $\mathbf{N}$ & Mean & Std. & Range \\
\hline nositive & 30 & 3.45 & 0.39 & $4.07-3.00$ \\
\hline negative & 30 & 2.06 & 0.30 & $2.53-1.33$ \\
\hline
\end{tabular}

\subsection{ERP recording}

This research applied the 32 channel Bluetooth wireless physiological feedback instrument NeXus-32 (Holland Mind Media Company) as the test device. The electrode impedance is $5 \mathrm{k} \Omega$, the brain wave record frequency is $250 \mathrm{~Hz}$, and the document filtering with $0.5-60 \mathrm{~Hz}$. The noise was filtered through BioTrace + software, taking the eye movement signal of maximum amplitude (over $80 \mu \mathrm{V}$ ) appearing in each signal (Chuang \& Chen, 2004; Onton et al., 2006) and the frontal lobe signal with frequency larger than $20 \mathrm{~Hz}$ (Shackman et al., 2009) as the standard. The document of the brain wave test was processed and analyzed by applying the WINEEG 2.124.95 software. Brain wave segmentation was continuously recorded; the total time interval was 0 to $1000 \mathrm{~ms}$, from the appearance of stimulation to $1000 \mathrm{~ms}$ after the stimulation. EEG documents were transformed into the ERP format. ERP amplitude was selected during the interval from $680 \mathrm{~ms}$ to $860 \mathrm{~ms}$. Afterwards, the overlaying and averaging to the brain wave section for the subjects in the same sample group was performed, and the grand averaging of the brain wave amplitudes of all subjects in carrying out the statistical analysis.

\subsection{Procedure}

The subjects were required to stay in the recording room with sound insulation effect and the environment light was usually the daily lamp. Before the test, the subjects sat on the chairs with their eyes about $60 \mathrm{~cm}$ from the center of the screen. After confirming the subjects understood the testing procedures, the test started. As shown in the Fig. 4, one cross diagram would initially appear on the screen center for staring and the time was 1000 ms. Afterwards, with the time interval of $1000 \mathrm{~ms}$ (ISI), the picture of products appeared for $2000 \mathrm{~ms}$; after another $1000 \mathrm{~ms}$ (ISI), it changed to the next group of samples. There were 90 groups of samples in total; each group of samples appeared once at random, with a break for 10 minutes in the middle. The time points for recording the brain wave document started after the samples appeared, after $2000 \mathrm{~ms}$.

\subsection{ERP analysis}

On the basis of the previous research (L Carretie et al., 1997; Holmes et al., 2003), F3, Fz, F4, C3, Cz, C4, P3, PZ, and P4 were selected and divided into zones: left-anterior (F3), middle-anterior (Fz), right-anterior (F4), left-central (C3), middle-central (Cz), right-central (C4), left-posterior (P3), middle-posterior $(\mathrm{Pz})$, and right-posterior (P4)). Figure 5 displays the ERP amplitudes for F3, Fz, F4, C3, Cz, C4, P3, PZ, and P4. The brain wave movements for all the stimulants were such that the LPC amplitude lowest peak appeared at the $\mathrm{Cz}$ site at approximately 644 ms and the highest peak approximately at $748 \mathrm{~ms}$; then the wave shape descended, forming one complete LPC wave shape at $680 \mathrm{~ms}$ to $800 \mathrm{~ms}$. Therefore, the brain wave selected the LPC component after the appearance of the target object during the selecting time interval, which is the average amplitude between approximately 680 ms to 800 ms. This measurement interval referred to the previous N600 (Brown et al., 2012; Schindler et al., 2015).

In terms of the detection of brain wave, the Repeated Measures ANOVA was applied to detect the LPC amplitude and ERP document for watch shape. With respect to the LPC amplitude, MANOVA detected the factors, including: emotion (positive, negative and neutral), anterior-posterior causality (anterior, central and posterior), and the left-right scalp region (left, medial, and right) of the scalp electrode locations. With respect to the watch shape, MANOVA detected the factors, including: watch frame shape (round, ellipse, square, rectangle, triangle and arc), frame proportion (1:1 and 1:1.5), frame $\mathrm{R}$ angle (with $\mathrm{R}$ angle and without $\mathrm{R}$ angle), watch pattern (non-curving, point curving, line curving, point-line curving, multi-information, line curving (black), intelligent (black-white), and intelligent color)), watch surface content (tradition and intelligence), watch surface background (white and black), and 
surface color (black, white and color). The second-time MANOVA performed the double-factor MANOVA analysis in accordance with the significant factors to ascertain any potential significant factor. For Non-Sphericity, F detection calibrates the freedom with G-G (Greenhouse-Geisser Correction). The [Post-Hoc Comparison] uses [Bonferroni Corrections] for comparison.

\section{Results}

\subsection{LPC effect (600-800 ms)}

Table 3 indicates the LPC average amplitude and standard deviation for the positive, negative and neutral stimulants. The average amplitude (standard deviation) of positive stimulant is $0.89(1.41)$, the average amplitude (standard deviation of negative stimulant is 1.64(1.26), and the average amplitude (standard deviation of neutral stimulant) is $0.37(1.60)$. The neutral stimulant is obviously lower than the positive and negative stimulants. Generally speaking, due to the neutral stimulant having no elements related to emotions, the subjects will not produce any emotional reaction (Ito et al., 1998). The positive, negative and neutral stimulants will all arouse high amplitude to the afterbrain.

Table 4, with respect to the overall detection of MANOVA to LPC, the emotions have the main effect $(F[2,30]=5.51, p<.05)$. Moreover, emotion $x$ leftright factor has the interactive effect $(F[4,60]=2.84, p<.05, \varepsilon=.68)$ and anterior-posterior $x$ left-right factor has the interactive effect $(F[4,60]=3.02, p$ $=.05, \varepsilon=.63$ ). The detection of the double-factor MANOVA in a positive vs. neuronal comparison identified that emotion and the left-right factor do not have the interactive effect $(p=.12)$, and through the detection of double-factor MANOVA negative vs. neuronal it found that emotions and the left-right factor do not have the interactive effect $(F[2,30]=4.43, p<.05, \varepsilon=.73)$. After the post detection, the amplitude of the negative in the left, medial, and right zones is obviously larger than the neuronal (respectively $F[1,15]=5.08, p<.05 ; F[1,15]=9.46, p<.01 ; F[1,15]=9.45, p<.01$ ), and that through the detection of double-factor MANOVA that a positive vs. negative comparison showed that emotion and left-right factor do not have the interactive effect $(p=.90)$.

Table 4

LPC amplitude results for MANOVA analysis for positive, negative and

\begin{tabular}{|c|c|c|c|c|c|}
\hline items & MS & $\mathbf{F}$ & Sig. & & Amp. \\
\hline emotion & 83.16 & 5.51 & 0.02 & * & \\
\hline anterior-posterior & 3.16 & 0.51 & 0.51 & & \\
\hline left-right & 0.26 & 0.83 & 0.45 & & \\
\hline emotion $\mathrm{x}$ anterior-posterior & 0.17 & 0.05 & 0.94 & & \\
\hline emotion $\mathrm{x}$ left-right & 0.51 & 2.84 & 0.03 & * & \\
\hline neuronal $x$ positive & 0.48 & 2.58 & 0.12 & & \\
\hline neuronal $x$ negative & 0.33 & 4.43 & 0.03 & * & \\
\hline neuronal $\mathrm{x}$ negative at left & 9.20 & 5.08 & 0.04 & * & Neu. $<$ Neg. \\
\hline neuronal $x$ negative at medial & 14.89 & 9.46 & 0.01 & 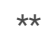 & Neu. $<$ Neg. \\
\hline neuronal $\mathrm{x}$ negative at right & 15.28 & 9.45 & 0.01 & ** & Neu. $<$ Neg. \\
\hline anterior-posterior $\mathrm{x}$ left-right & 0.33 & 3.02 & 0.05 & * & \\
\hline
\end{tabular}

\subsection{Influence of designed shape on emotion}

Table 5 indicates the LPC average amplitude of frame and surface under the positive and negative stimulants. The average amplitudes (standard deviation) of frame under the positive and negative stimulants are 0.65 (2.42) and 1.49 (1.69), respectively; the average amplitudes (standard deviation) of the surface under the positive and negative stimulants are 0.77 (2.09) and 1.50 (2.19), respectively. 
Table 5

LPC average amplitudes for frame and surface with positive and negative stimulants.

\begin{tabular}{|c|c|c|c|c|c|c|}
\hline \multirow[t]{2}{*}{ Type } & \multirow[t]{2}{*}{ Element } & & \multicolumn{2}{|c|}{ positive } & \multicolumn{2}{|c|}{ negative } \\
\hline & & & mean & SD & mean & SD \\
\hline \multirow[t]{10}{*}{ Frame } & \multirow[t]{6}{*}{ Shape } & Circle & 0.66 & 2.64 & 0 & 0 \\
\hline & & Ellipse & -1.74 & 5.51 & 1.75 & 3.03 \\
\hline & & Square & 0.98 & 1.34 & 1.2 & 1.95 \\
\hline & & Rectangle & 1.51 & 1.96 & 1.51 & 1.88 \\
\hline & & Triangle & 1.27 & 2.7 & 1.86 & 1.61 \\
\hline & & Arc & 0.91 & 1.75 & 1.84 & 3.03 \\
\hline & \multirow[t]{2}{*}{ Ratio } & $1: 1$ & 0.86 & 1.37 & 1.87 & 1.17 \\
\hline & & $1: 1.5$ & 0.76 & 1.64 & 1.21 & 1.55 \\
\hline & \multirow[t]{2}{*}{ Radius } & Radius & 0.93 & 1.18 & 2.18 & 1.46 \\
\hline & & No radius & 0.34 & 4.08 & 1.48 & 1.23 \\
\hline \multirow[t]{14}{*}{ Surface } & \multirow[t]{8}{*}{ Pattern } & No depict & 1.76 & 2.49 & 1.94 & 2.28 \\
\hline & & Point depict & 1.71 & 1.75 & 0.88 & 3.21 \\
\hline & & Line depict & 0.71 & 2.55 & 1.24 & 2.29 \\
\hline & & Point and line depict & -0.32 & 3 & 0.94 & 1.86 \\
\hline & & Line depict (Black) & 1.33 & 2.22 & 2.14 & 2.12 \\
\hline & & Information & 0.05 & 2.86 & 2.11 & 1.76 \\
\hline & & Intelligent (black and white) & 0.91 & 2.56 & 2.19 & 1.81 \\
\hline & & Intelligent (Colorful) & 0.33 & 2.36 & 0.89 & 4.01 \\
\hline & \multirow[t]{2}{*}{ Content } & Traditional & 0.87 & 1.18 & 1.54 & 1.03 \\
\hline & & Intelligent & 0.62 & 1.85 & 1.54 & 2.58 \\
\hline & \multirow[t]{2}{*}{ Background } & White & 1.06 & 1.37 & 1.54 & 1.3 \\
\hline & & Black & 0.56 & 1.6 & 1.54 & 1.39 \\
\hline & \multirow[t]{2}{*}{ Color } & Black and White & 0.88 & 1.12 & 1.63 & 1.05 \\
\hline & & Colorful & 0.33 & 2.36 & 0.89 & 4.01 \\
\hline
\end{tabular}

By comparing the values of average amplitudes, the amplitude for the frame shape is the highest with the negative triangle, and the negative arc takes second place, while the amplitude for the positive ellipse shape is the lowest. The amplitude for the frame proportion is the highest with the negative 1:1, and the lowest for positive 1:1.5. The amplitude for the frame $R$ angle is the highest with the negative $R$ angle, and the lowest for the positive without $R$ angle. In addition, the amplitude for the surface pattern is the highest with negative intelligence (black-white), and the negative line curving (black) takes second place, while the amplitude for the positive intelligent point curving is the lowest. The amplitude for the surface background is the highest with the negative white and black, and the lowest for positive black. The amplitude for surface color is the highest with the negative white and black, and the lowest for positive black. The amplitude for surface color is the highest with the negative black-white, and the lowest for positive color. In conclusion, regardless of the frame or surface, the LPC average amplitudes for all negative stimulants are the highest, and the lowest for positive stimulants.

Table 6 indicates the two-factor MANOVA comparison for neuronal vs. positive, and neuronal vs. negative emotions. In terms of the frame shape, the triangle and arc with negative emotions are significantly higher than the neutral $(F[1,15]=7.08, p<.05)$, while the other shapes (round, ellipse, square and rectangle) have no significant difference to any emotion. With respect to proportion, only the negative emotion 1:1 proportion is significantly higher than the neutral $(F[1,15]=13.14, p<.01)$. In terms of $R$ angle, the negative emotion with $R$ angle and without $R$ angle is significantly higher than the neutral $(F[1,15]=14.89, p<.01 ; F[1,15]=5.33, p<.05)$. 
Table 6

MANOVA results for positive, negative, and neuronal emotions.

\begin{tabular}{|c|c|c|c|c|c|c|c|c|}
\hline Type & Element & & emotion & MS & $\square$ & Sig. & & Amp. \\
\hline \multirow[t]{20}{*}{ Frame } & \multirow[t]{12}{*}{ Shape } & \multirow[t]{2}{*}{ Circle } & neuronal vs. positive & 0.69 & 0.17 & 0.69 & & \\
\hline & & & neuronal vs. negative & 1.10 & 1.03 & 0.33 & & \\
\hline & & \multirow[t]{2}{*}{ Ellipse } & neuronal vs. positive & 35.57 & 2.41 & 0.14 & & \\
\hline & & & neuronal vs. negative & 15.25 & 3.02 & 0.10 & & \\
\hline & & \multirow[t]{2}{*}{ Square } & neuronal vs. positive & 2.97 & 1.34 & 0.27 & & \\
\hline & & & neuronal vs. negative & 5.45 & 2.09 & 0.17 & & \\
\hline & & \multirow[t]{2}{*}{ Rectangle } & neuronal vs. positive & 10.43 & 3.79 & 0.07 & & \\
\hline & & & neuronal vs. negative & 28.16 & 14.32 & 0.12 & & \\
\hline & & \multirow[t]{2}{*}{ Triangle } & neuronal vs. positive & 21.55 & 4.22 & 0.24 & & \\
\hline & & & neuronal vs. negative & 17.64 & 7.08 & 0.02 & * & Neu. $<$ Neg. \\
\hline & & \multirow[t]{2}{*}{ Arc } & neuronal vs. positive & 13.17 & 4.67 & 0.34 & & \\
\hline & & & neuronal vs. negative & 39.16 & 4.82 & 0.03 & * & Neu. $<$ Neg. \\
\hline & \multirow[t]{4}{*}{ Ratio } & \multirow[t]{2}{*}{$1: 1$} & neuronal vs. positive & 1.92 & 1.86 & 0.19 & & \\
\hline & & & neuronal vs. negative & 17.99 & 13.14 & 0.002 & $\star \star$ & Neu. $<$ Neg. \\
\hline & & \multirow[t]{2}{*}{$1: 1.5$} & neuronal vs. positive & 1.23 & 0.48 & 0.50 & & \\
\hline & & & neuronal vs. negative & 5.64 & 1.94 & 0.18 & & \\
\hline & \multirow[t]{4}{*}{ Radius } & \multirow[t]{2}{*}{ Radius } & neuronal vs. positive & 2.53 & 1.74 & 0.21 & & \\
\hline & & & neuronal vs. negative & 26.26 & 14.89 & 0.002 & ** & Neu. $<$ Neg. \\
\hline & & \multirow[t]{2}{*}{ No radius } & neuronal vs. positive & 0.01 & 0.001 & 0.97 & & \\
\hline & & & neuronal vs. negative & 9.84 & 5.33 & 0.04 & * & Neu. $<$ Neg. \\
\hline \multirow[t]{20}{*}{ Surface } & \multirow[t]{16}{*}{ Pattern } & \multirow[t]{2}{*}{ No depict } & neuronal vs. positive & 15.48 & 5.05 & 0.04 & * & Neu. $<$ Pos.. \\
\hline & & & neuronal vs. negative & 19.78 & 10.59 & 0.01 & $\star \star$ & Neu. $<$ Neg. \\
\hline & & \multirow[t]{2}{*}{ Point depict } & neuronal vs. positive & 14.33 & 10.62 & 0.01 & ** & Neu. $<$ Pos. \\
\hline & & & neuronal vs. negative & 2.05 & 0.28 & 0.60 & & \\
\hline & & \multirow[t]{2}{*}{ Line depict } & neuronal vs. positive & 0.94 & 0.37 & 0.55 & & \\
\hline & & & neuronal vs. negative & 5.99 & 1.46 & 0.25 & & \\
\hline & & \multirow[t]{2}{*}{ Point and line depict } & neuronal vs. positive & 3.80 & 0.68 & 0.42 & & \\
\hline & & & neuronal vs. negative & 2.57 & 0.82 & 0.38 & & \\
\hline & & \multirow[t]{2}{*}{ Line depict (Black) } & neuronal vs. positive & 7.32 & 1.27 & 0.28 & & \\
\hline & & & neuronal vs. negative & 24.95 & 6.22 & 0.03 & * & Neu. $<$ Neg. \\
\hline & & \multirow[t]{2}{*}{ Information } & neuronal vs. positive & 0.81 & 0.14 & 0.71 & & \\
\hline & & & neuronal vs. negative & 24.18 & 8.06 & 0.01 & $\star \star$ & Neu. $<$ Neg. \\
\hline & & \multirow[t]{2}{*}{ Intelligent (black and white) } & neuronal vs. positive & 2.35 & 0.81 & 0.38 & & \\
\hline & & & neuronal vs. negative & 26.58 & 11.99 & 0.003 & $\star \star$ & Neu. $<$ Neg. \\
\hline & & \multirow[t]{2}{*}{ Intelligent (Colorful) } & neuronal vs. positive & 0.01 & 0.003 & 0.96 & & \\
\hline & & & neuronal vs. negative & 2.17 & 0.23 & 0.64 & & \\
\hline & Content & Traditional & neuronal vs. positive & 2.03 & 1.33 & 0.27 & & \\
\hline & & & neuronal vs. negative & 10.93 & 6.14 & 0.03 & $\star$ & Neu. $<$ Neg. \\
\hline & & Intelligent & neuronal vs. positive & 0.51 & 0.27 & 0.61 & & \\
\hline & & & neuronal vs. negative & 10.98 & 2.51 & 0.13 & & \\
\hline
\end{tabular}




\begin{tabular}{|c|c|c|c|c|c|c|c|c|}
\hline Type & Element & & emotion & MS & $\square$ & Sig. & & Amp. \\
\hline & \multirow[t]{4}{*}{ Background } & \multirow[t]{2}{*}{ White } & neuronal vs. positive & 3.79 & 3.49 & 0.08 & & \\
\hline & & & neuronal vs. negative & 10.96 & 5.70 & 0.03 & * & Neu. $<$ Neg. \\
\hline & & \multirow[t]{2}{*}{ Black } & neuronal vs. positive & 0.29 & 0.12 & 0.73 & & \\
\hline & & & neuronal vs. negative & 10.93 & 4.78 & 0.05 & * & Neu. $<$ Neg. \\
\hline & \multirow[t]{4}{*}{ Color } & \multirow[t]{2}{*}{ Black and White } & neuronal vs. positive & 2.07 & 1.61 & 0.22 & & \\
\hline & & & neuronal vs. negative & 12.75 & 7.51 & 0.02 & * & Neu. $<$ Neg. \\
\hline & & \multirow[t]{2}{*}{ Colorful } & neuronal vs. positive & 0.01 & 0.003 & 0.96 & & \\
\hline & & & neuronal vs. negative & 2.17 & 0.23 & 0.64 & & \\
\hline
\end{tabular}

In terms of the surface pattern, the negative emotion patterns, including the non-curving, point curving, multi-information, line curving (black) and intelligent (black-white) LPC, the amplitude is significant higher than the neutral (respectively $F[1,15]=5.05, p<.05 ; F[1,15]=10.62, p=.01 ; F[1,15]=$ $8.06, p<.05 ; F[1,15]=11.99, p<.01)$, and the positive emotion of non-curving is also significant higher than the neutral $(F[1,15]=7.08, p<.05)$. In addition, in terms of the content, the content of the negative traditional form is significant higher than the neutral $(F[1,15]=6.14, p<.05)$. In terms of the background, the white and black background of the negative emotion is significant higher than the neutral (respectively, $F[1,15]=5.70, p<.05$ and $F[1$, $15]=4.78, p-=.05)$. In terms of the color, the black-white surface of the negative emotion is significantly higher than the neutral $(F[1,15]=7.51, p<.05)$.

\section{Discussion}

This research takes the watch as the case example, applies visual geometric shapes with high and low emotion valence (positive and negative emotion) to measure how ERP detects different product designing features influencing the emotional reaction of the brain, to understand the relationship between the designing elements of product and the emotional reaction, which facilitates the understanding of the preferences of consumers and enhance the purchase chance. The previous research has proven that emotion plays an important decision-making role in purchasing (Laros \& Steenkamp, 2005). The ERP results indicate that negative emotions shaped with low valence can improve the LPC amplitude. The LPC amplitude of positive emotion valence is lower than the shape of negative emotion. The afterbrain is the major brain zone for processing the positive and negative emotions. The distribution range for the positive and negative emotions in the scalp topographic map differs. Although the color is the main factor deciding the product emotion (Jang \& Kim, 2007), appearance, proportion and pattern are also influential factors. We will next further discuss the designing factors significantly influencing the emotion valence.

\subsection{Loading degree of emotion influenced by the difficulty of aesthetic evaluation}

This research identifies that the negative stimulant will arouse the higher LPC amplitude more than the positive stimulant will. This result is consistent with the previous result, which indicates that LPC is influenced by the attention resource of psychological distribution, and that negative emotional pictures will arouse the higher LPC amplitude more than the positive emotion pictures will (Ito et al., 1998; Kern et al., 2005; Lang et al., 2001; Wood \& Kisley, 2006). On the basis of limited psychological distribution, people will prioritize in processing the reasons of issues with threats. This research focuses on the evaluation of shape aesthetic perception, which differs from using stimulants with intensive and threatening properties in the past. Generally speaking, the long fixation time usually involves a number of psychological processes (Rayner, 1998). In addition, the visual difficulty of image (Rayner, 1998; Rayner \& Duffy, 1986) is one of the factors influencing the attention time length. The longer the attention time, the greater the distribution of attention resources! The subjects are able to decide to perform the evaluation related to the stimulation in accordance with their own demands and specific environment, as well as distribute more psychological resources (Luo \& Huang, 2006). Whether the stimulants require rigorous consideration is the key to influencing the LPC amplitude. The operation of this research focuses on the processing and judgment of aesthetic shapes, which enables the subjects to prioritize to consider the strongest stimulant influencing the aesthetic perception, which is possibly that the shape with negative emotion is noticed initially, thereby enhancing the LPC amplitude. On the contrary, the subjects employ comparatively less mental resources with respect to the shape with aesthetic factors; thus, the LPC reaction aroused will be lower.

\subsection{Visual zone of brain processing aesthetic evaluation}

The visual zone of the afterbrain is one of the important zones for aesthetic evaluation. In this research, the LPC effect distribution for the scalp topographic map of positive and negative evaluations is different. The distribution of positive emotions is centralized in the central and afterbrain zones, and the negative emotion is evenly distributed in the afterbrain. The visual cortex for these zones is located in the occipital lobe at the back of the brain, which is the zone mainly responsible for processing visual information (Zeki et al., 1991). According to the theory of information aesthetics, there is a relation between the aesthetic emotion and visual information (Eysenck, 1968). Regardless of the aesthetic evaluation of positive or negative emotions, the visual zone can be regarded as the reference for the aesthetic value in judging where it belongs in the brain zone.

\subsection{Feature influencing product affect valence}

The shape, pattern and color of products play the decision-making role in expressing the product emotion; they can change the emotions and reaction of consumers to the product. Previous research identified that the new, complex and inconsistent articles in the image could attract the long-time staring of 
subjects (Henderson et al., 1999; Loftus \& Mackworth, 1978). Therefore, in terms of the frame, the sharpness (e.g. triangle) or special shapes (e.g. arc) may arouse inconsistent feelings in subjects and the negative emotions, leading to higher LPC amplitude. The triangle shape elicits a negative emotional reaction; conversely, the round shape elicits positive emotions. This result is consistent with the results of Bar \& Neta (2006), Hsu et al. (2000), and Ohkura et al. (2008) who conclude that round articles are perceived as more beautiful than the sharp articles; consumers prefer the appearance with curves rather than with sharp angles. In terms of the frame proportion, consumers prefer the proportion of 1:1 in regard to the appearance of products (Jung \& Badke-Schaub, 2017). In this research, the triangle with the 1:1 proportion of negative emotion obtained the highest LPC amplitude among all shapes, which possibly implies enhancing the overall 1:1 negative emotional reaction. Angles, e.g. V shape or triangle, etc., will deliver negative emotion information (e.g. threat) (Larson et al., 2012). Thus, we may conclude that the frame with a triangular appearance will arouse negative emotions.

In terms of the surface pattern, the designing elements and arrangement with the clear visual elements and complex distribution will arouse the higher LPC amplitude. The water pattern belongs to the radial balance in the principle of aesthetic forms, which refers to taking the point as the center, surrounded by the circular arrangement of radiation or roundness to form the type of radiation, which enables the entire shape and structure to be stable and produce the visual effect of rhythm (Chiu et al., 2006). If the non-curving, point curving, information and intelligent patterns lack the significant radiation lining arrangement, in terms of the aesthetic form, the imbalance will produce visual instability and psychological imbalance, thereby arousing a strong negative emotional reaction. In addition, the drawings complying with the balance principle will avoid the perceptional mess or laxity; the subjects will be able to effectively browse the drawing (Locher \& Nodine, 1989).

In terms of the surface content, the product with a new appearance and white-black color will arouse the higher LPC amplitude to the greatest degree, bringing sensual fantasy, entertainment and happy feelings for the consumers (Hirschman et al., 1982). This differs from Baxter's (1995) belief that the consumers will be influenced by old attractions, as they are able to identify the product of the same type they used to use or prefer; the preference degree for the old type is higher than for the new type. The results of this research reveal that the consumers of traditional surface products maintain the visual feature images due to their long time design, which will reflect negative emotions regarding novelty. On the contrary, the new intelligent surface content will more easily arouse greater feelings of interest and attention among the subjects. With respect to the surface background and color, the color is the final element attracting the consumers, as well as an important element in deciding the product emotion and convincing them to purchase (Jang \& Kim, 2007). In this study, the product applied the white-black background image, which delivers higher negative emotion than the color, and the white-black can enhance the brain wave focus of people. This is consistent with the results of Wang et al. (2016) and Nijdam (2009) who indicate that the black color will arouse a stronger emotion reaction than white color will. Moreover, the white color disseminates a positive impression to remind the users of the clean, pure, fresh, beautiful, gentle and natural emotions (Saito, 1996), while the black color is dark and blurry (Na \& Suk, 2014). Therefore, it is extremely important to select the appropriate color and deliver the required product emotion in the product design.

\section{Conclusion And Suggestions}

This research discusses the influence of visual watch design features on the subjects. The research proves that the sharp appearance (e.g. triangle) or special shapes (e.g. arc) will arouse inconsistent negative feelings. The old type products (e.g. round and square) will arouse more negative emotions than the new types. Due to the brain memory retaining the previous fixed visual feature image, if the type is not new, it will produce higher LPC amplitude. In addition, the black-white will deliver high negative emotion than the color matching. This research takes brain waves as the objective evaluation tool and considers cognitive bias for its subjective questionnaire, and the design features of the watch will indeed measure the obvious ERP effect. It is expected that the research results will promote the EPP measurement tool to be integrated into the other designing subjects or research. Moreover, the combination of different designing elements streamlined by this research will also serve as the designing parameters in the innovation of digit models. According to the designing factors that can effectively influence the people's emotion, the systematic emotion design is presented, which is appropriate to the actual product design.

It is recommended that future research includes: (1) improving the typicality of neutral stimulants, e.g. scenery drawings, people, animals, etc., deemed in this research as overly complex, which may stimulate some brain zones and cause high ERP amplitudes. It is recommended that future research use gray color pictures as the neutral stimulants, as it can reduce unnecessary stimulation. (2) Increase the intelligent surface and color background type: Although this research includes these samples, the number is not equal in proportion, which may emotionally imbalance the brain wave amplitude. This will enable the selection of more different types of intelligent surfaces and colors for research in the future to equalize the proportion of samples quantity. (3) Improve the visual sensitivity of subjects as the LPC effect of brain waves is the negative stimulant that is higher than the positive and neutral stimulants. But the subjects are still unable to effectively distinguish the differences between the positive and neutral stimulants. It is recommended to initially perform the appropriateness test (including the thinking and sensitivity survey) in terms of selecting the subjects so as to select the proper subjects, as well as improve the designing sensitivity of subjects to the product shape, appearance, internal designing elements and minor differences.

\section{Declarations}

- Ethics approval and consent to participate: The ethics approval granted by the Research Ethics Committee National Taiwan University (NTU-REC No. 201712EM022).

- - Consent to publish: I Ching-Yi Wang give my consent for information about myself to be published in Behavioral and Brain Functions, Ching-Yi Wang. I understand that the information will be published without my relative's name attached, but that full anonymity cannot be guaranteed. I 
understand that the text and any pictures or videos published in the article will be freely available on the internet and may be seen by the general public. The pictures, videos and text may also appear on other websites or in print, may be translated into other languages or used for commercial purposes. I have been offered the opportunity to read the manuscript.

- - Availability of data and materials: Not applicable.

- - Competing interests: The authors declare that they have no competing interests

- - Funding: Not applicable.

- - Authors' Contributions: All authors have approved the manuscript before submission, including the names and order of authors, and that all authors receive the submission and all substantive correspondence with editors, as well as the full reviews, verifying that all data, figures, materials (including reagents), and code, even those developed or provided by other authors, comply with the transparency and reproducibility standards of both the field and journal.

- - Acknowledgements: Not applicable.

\section{References}

1. Armbruster D, Suchert V, Gärtner A, Strobel A. Threatening shapes: the impact of simple geometric configurations on peripheral physiological markers. Physiol Behav. 2014;135:215-21.

2. Bar M, Neta M. Humans prefer curved visual objects. Psychol Sci. 2006;17(8):645-8.

3. Bar M, Neta M. Visual elements of subjective preference modulate amygdala activation. Neuropsychologia. 2007;45:2191-200.

4. Baxter MR. (1995). Product Design: Practical methods for the systematic development of new products. Chapman \& Hall.

5. Berridge KC, Robinson TE. Parsing reward. Trends Neurosci. 2003;26(9):507-13.

6. Blazhenkova O, Melisa MK. Angular Versus Curved Shapes: Correspondences and Emotional Processing. Perception. 2017;47(1):67-89.

7. Brown KW, Goodman RJ, Inzlicht M. Dispositional mindfulness and the attenuation of neural responses to emotional stimuli. Social Cognitive Affective Neuroscience. 2012;8(1):93-9.

8. Brown S, Gao X, Tisdelle L, Eickhoff SB, Liotti M. Naturalizing aesthetics: Brain areas for aesthetic appraisal across sensory modalities. Neuroimage. 2011;58:250-8.

9. Carretié L, Hinojosa JA, Mercado F. Cerebral patterns of attentional habituation to emotional visual stimuli. Psychophysiology. 2003;40(3):381-8.

10. Chiu YF, Chang SU, Li HC. High school art field course auxiliary teaching reference manual 3: Basic design. Taipei City: National Taiwan Art Education Center; 2006.

11. Chuang YL, Chen IP. (2004). The spatial distribution of visual attention on radial compositions. Unpublished master's thesis, National Institute of Applied Art, National Chiao Tung University, Hsinchu.

12. Coates D. (2003). Watches Tell More Than Time: Product Design. Information, and the Quest for Elegance.

13. Cuthbert BN, Schupp HT, Bradley MM, Birbaumer N, Lang PJ. Brain potentials in affective picture processing: Covariation with autonomic arousal and affective report. Biol Psychol. 2000;52:95-111.

14. Delplanque S, Lavoie ME, Hot P, Silvert L, Sequeira H. Modulation of cognitive processing by emotional valence studied through event-related potentials in humans. Neurosci Lett. 2004;356:1-4.

15. Dolcos F, Cabeza R. Event-related potentials of emotional memory: encoding pleasant, unpleasant, and neutral pictures. Cognitive Affective Behavioral Neuroscience. 2002;2(3):252-63.

16. Drevets WC, Raichle ME. Reciprocal suppression of regional cerebral blood flow during emotional versus higher cognitive processes: Implications for interactions between emotion and cognition. Cogn Emot. 1998;12:353-85.

17. Eysenck HJ. An experimental study of aesthetic preference for polygonal figures. J Gen Psychol. 1968;79:3-17.

18. Fechner GT. Vorschule der Ästhetik. Leipzig: Breitkopf \& Hartel; 1876.

19. Flaisch T, Hacker F, Renner B, Schupp HT. Emotion and the processing of symbolic gestures: An event-related brain potential study. Social Cognitive Affective Neuroscience. 2011;6(1):109-18.

20. Flaisch T, Stockburger J, Schupp HT. Affective prime and target picture processing: an ERP analysis of early and late interference effects. Brain Topogr. 2008;20:183-91.

21. Frühholz S, Jellinghaus A, Herrmann M. Time course of implicit processing and explicit processing of emotional faces and emotional words. Biol Psychol. 2011;87:265-74.

22. Hajcak G, Nieuwenhuis S. Reappraisal modulates the electrocortical response to unpleasant pictures. Cognitive Affective Behavioral Neuroscience. 2006;6(4):291-7.

23. Hajcak G, Moser JS, Simons RF. Attending to affect: appraisal strategies modulate the electrocortical response to arousing pictures. Emotion. 2006;6(3):517-22.

24. Hamilton DL, Fallot RD. Information salience as a weighting factor in impression formation. J Pers Soc Psychol. 1974;30(4):444-8.

25. Hansen F, Kenning P, Plassmann H. Contributions to decision neuroscience. J Econ Psychol. 2010;31:764-6. 
26. Henderson JM, Weeks PA, Hollingworth A. The effects of semantic consistency on eye movements during complex scene viewing. J Exp Psychol Hum Percept Perform. 1999;25:210-28.

27. Herbert C, Junghofer M, Kissler J. Event-related potentials to emotional adjectives during reading. Psychophysiology. 2008;45(3):487-98.

28. Hirschman EC, Holbrook MB. (1982). Hedonic consumption: emerging concepts, methods and propositions. The Journal of Marketing, $92-101$.

29. Hoyer WD, Stokburger-Sauer NE. The role of aesthetic taste in consumer behavior. J Acad Mark Sci. 2012;40(1):167-80.

30. Hsu SH, Chuang MC, Chang CC. A semantic differential study of designers' and users' product form perception. Int J Ind Ergon. 2000;25(4):375-91.

31. Ito TA, Larsen JT, Smith NK, Cacioppo JT. Negative information weighs more heavily on the brain: The negativity bias in evaluative categorizations. J Pers Soc Psychol. 1998;75(4):887-900.

32. Jacobsen T, Höfel L. Aesthetic judgments of novel graphic patterns: analyses of individual judgments. Percept Mot Skills. 2002;95(3):755-66.

33. Jang NS, Kim SB. The product color effect on product color preference, product image and product attitude. J Korean Neurosurg Soc. 2007;20:7988.

34. Jenkins S, Brown R, Rutterford N. (2009). Comparing thermographic, EEG, and subjective measures of affective experience during simulated product interactions. International journal of Design, 3(2).

35. Jordan PW. Human factors for pleasure in product use. Applied ergonomics. 1998;29(1):25-33.

36. Jung JY, Badke-Schaub P. The Impact of Aesthetic Preference in Product Design-Golden Ratio and Korean's Preference Proportion. Archives of Design Research. 2017;30(4):5-14.

37. Junghofer M, Peyk P, Kissler J, Herbert C, Flaisch T, Stockburger J, Schupp H. Rapid serial visual presentation in studies on early motivated attention: an overview. Psychophysiology. 2004;41:17.

38. Kern RP, Libkuman TM, Otani H, Holmes K. Emotional stimuli, divided attention, and memory. Emotion. 2005;5(4):408-17.

39. Kissler J, Herbert C, Peyk P, Junghofer M. Buzzwords: Early cortical responses to emotional words during reading. Psychol Sci. 2007;18(6):475-80.

40. Lang PJ, Bradley MM, Cuthbert BN. (2001). International Affective Picture System: Technical Manual and Affective Ratings, NIMH Center for the Study of Emotion and Attention.

41. Laros F, Steenkamp J. Emotions in consumer behavior: A hierarchical approach. J Bus Res. 2005;10:1437-45.

42. Larson CL, Aronoff J, Steuer EL. Simple geo-metric shapes are implicitly associated with affective value. Motivation Emotion. 2012;36:404-13.

43. Lin MH, Fang YM, Wang CY. A preliminary study of applying erp on users'reactions to web pages with different presentation formats. Bulletin of Japanese Society for the Science of Design. 2011a;57(5):89-98.

44. Lin MH, Wang CY, Cheng SK, Cheng SH. An event-related potential study of semantic style-match judgments of artistic furniture. Int J Psychophysiol. 2011b;82(2):188-95.

45. Locher P. The Contribution of Eye-Movement Research to An Understanding of the Nature of Pictorial Balance Perception: A Review of the Literature. Empirical Studies of the Arts. 1996;14(2):143-63.

46. Locher P, Nodine C. The Perceptual Value of Symmetry. Comput Math Appl. 1989;16:475-84.

47. Loftus GR, Mackworth NH. Cognitive determinations of fixation location during pictures viewing. J Exp Psychol Hum Percept Perform. 1978;4:56572.

48. Luo YJ, Huang YX. Temporal course of emotional negativity bias: An ERP study. Neurosci Lett. 2006;398:91-6.

49. Mickley Steinmetz KR, Kensinger EA. The effects of valence and arousal on the neural activity leading to subsequent memory. Psychophysiology. 2009;46:1190-9.

50. Montoya P, Sitges C. Affective modulation of somatosensory-evoked potentials elicited by tactile stimulation. Brain Res. 2006;1068(1):205-12.

51. Na N, Suk HJ. (2014). The emotional characteristics of white for applications of product color design. Industrial Applications of Affective Engineering(pp. 253-264): Springer.

52. Nijdam NA. (2009). Mapping emotion to color. Book Mapping emotion to color, 2-9.

53. Norton D, Stark L. Eye movements and visual perception. Sci Am. 1971a;224:34-43.

54. Norton D, Stark L. Scanpaths in eye movements during pattern perception. Science. 1971b;171:308-11.

55. Norton D, Stark L. Scanpaths in saccadic eye movements while viewing and recognizing patterns. Vision Res. 1971c;11:929-42.

56. Ohkura M, Konuma A, Murai S, Aoto T. (2008). Systematic study for "kawaii" products (the second report)-commpmrison of "kawaii" colors and shapes. The SICE Annual Conference, 2008.

57. Olofsson JK, Nordin S, Sequeira H, Polich J. Affective picture processing: an integrative review of ERP findings. Biol Psychol. 2008;77(3):247-65.

58. Onton J, Westerfield M, Townsend J, Makeig S. Imaging human EEG dynamics using independent component analysis. Neuroscience Biobehavioral Reviews. 2006;30(6):808-22.

59. Palmer SE, Schloss KB, Xu Z, Prado-Leo'n LR. (2013). Music-color associations are mediated by emotion. Proceedings of the National Academy of Sciences, 110, 8836-8841.

60. Rajapakse RJ, Jayasinghe H, Tokuyama Y, Miyata K, Marasinghe A. (2009). The effect of variable base on perceiving gender kansei of 3D-shape. International Conference on The Biometrics and Kansei Engineering.

Page 13/17 
61. Rayner K. Eye movements in reading and in information processing: 20 years of research. Psychol Bull. 1998;124:372-422.

62. Rayner K, Duffy SA. Lexical complexity and fixation times in reading: Effects of word frequency, verb complexity, and lexical ambiguity. Memory Cognition. 1986;14:191-201.

63. Recio G, Sommer W, Schacht A. Electrophysiological correlates of perceiving and evaluating static and dynamic facial emotional expressions. Brain Res. 2011;1376:66-75.

64. Riegel M, Żurawski Ł, Wierzba M, Moslehi A, Klocek Ł, Horvat M, Grabowska A, Michałowski J, Jednoróg K, Marchewka A. Characterization of the Nencki Affective Picture System by discrete emotional categories (NAPS BE). Behavior research methods. 2016;48(2):600-12.

65. Russell JA. Core affect and the psychological construction of emotion. Psychological review. 2003;110(1):145-72.

66. Russell JA, Ward LM, Pratt G. Affective quality attributed to environments: A factor analytic study. Environment behavior. 1981;13(3):259-88.

67. Saito M. Comparative studies on color preference in Japan and other Asian regions, with special emphasis on the preference for white. Color Research Application. 1996;21:35-49.

68. Schacht A, Sommer W. Emotions in word and face processing: early and late cortical responses. Brain Cogn. 2009a;69:538-50.

69. Schacht A, Sommer W. Time course and task dependence of emotion effects in word processing. Cognitive Affective Behavioral Neuroscience. 2009b;9:28-43.

70. Schapkin SA, Gusev AN, Kuhl J. Categorization of unilaterally presented emotional words: an ERP analysis. Acta Neurobiol Exp. 2000;60:17-28.

71. Schindler S, Wegrzyn M, Steppacher I, Kissler J. Perceived communicative context and emotional content amplify visual word processing in the fusiform gyrus. J Neurosci. 2015;35(15):6010-9.

72. Schupp HT, Cuthbert BN, Bradley MM, Cacioppo JT, Ito T, Lang PJ. Affective picture processing: the late positive potential is modulated by motivational relevance. Psychophysiology. 2000;37:257-61.

73. Schupp HT, Junghöfer M, Weike Al, Hamm AO. The selective processing of briefly presented affective pictures: an ERP analysis. Psychophysiology. 2004;41:441-9.

74. Shackman AJ, McMenamin BW, Slagter HA, Maxwell JS, Greischar LL, Davidson RJ. Electromyogenic artifacts and electroencephalographic inferences. Brain Topogr. 2009;22(1):7-12.

75. Spreckelmeyer KN, Kutas M, Urbach TP, Altenmüller E, Münte TF. Combined perception of emotion in pictures and musical sounds. Brain research. 2006;1070(1):160-70.

76. Vuilleumier P. How brains beware: Neural mechanisms of emotional attention. Trends in Cognitive Sciences. 2005;9:585-94.

77. Wang C, Y., \& Chung YJ. Detecting the semantic differences of congruence, ambiguity, and incongruence in the picture-word matching task using the event-related potential. Journal of Design. 2017;22(1):25-45.

78. Wang HS, Lin HY, Wang MW. The study of using electroencephalogram to explore the relationship of perception and photo filter effects. Educational technology learning. 2016;4(2):119-36.

79. Wang J, Han W. The impact of perceived quality on online buying decisions: An event-related potentials perspective. Neuroreport. 2014;25:1091-8.

80. Wood S, Kisley MA. The negativity bias is eliminated in older adults: age-related reduction in event-related brain potentials associated with evaluative categorization. Psychol Aging. 2006;21:815-20.

81. Yarbus A. Eye movements and Vision. New York: Plenum Press; 1967.

82. Zeki S, Watson JDG, Lueck CJ, Friston KJ, Kennard C, Frackowiak RSJ. A Direct Demonstration of Functional Specialization in Human Visual Cortex. The Journal of Neuroscience. 1991;17(3):641-9.

\section{Figures}


$\mathrm{HIGH}$

AROUSAL

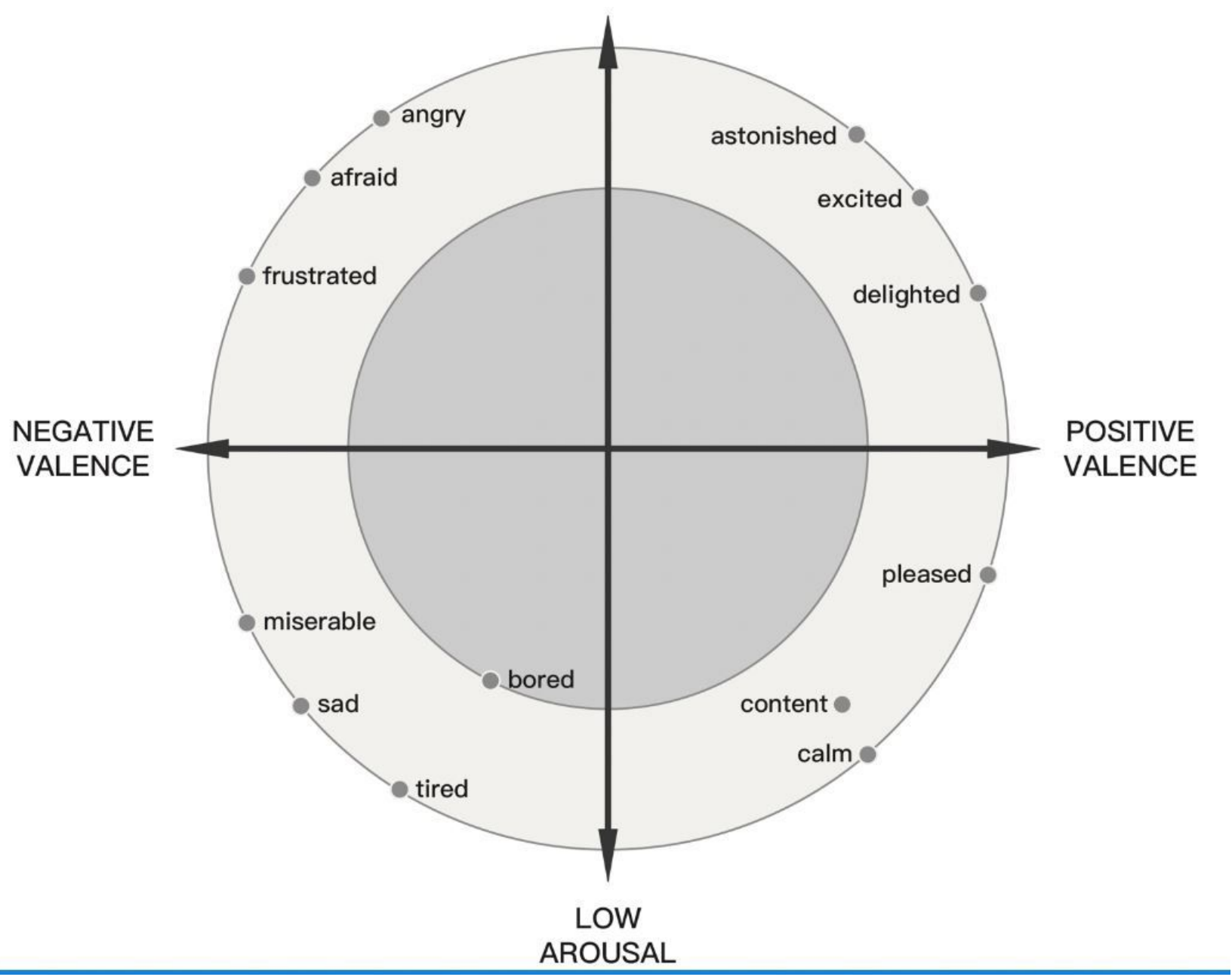

Figure 1

Dimension of affect: horizontal axis is valance; vertical axis is arousal (russell, 2003) 


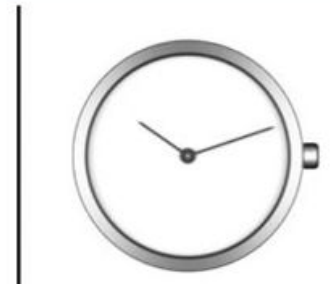

Circle

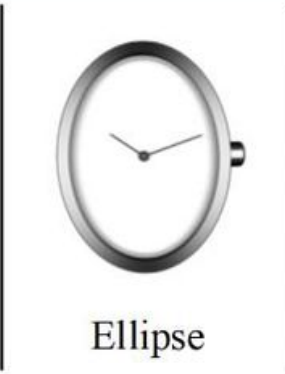

Ellipse

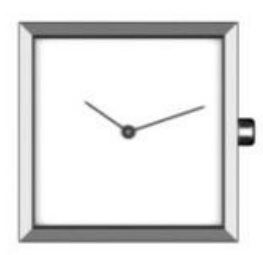

Square

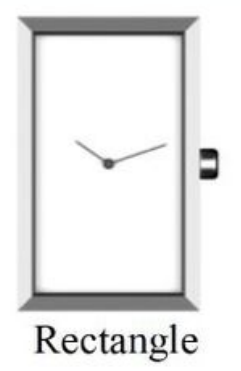

(a) frame

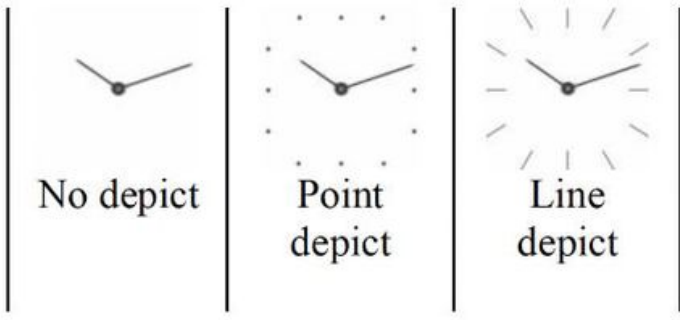

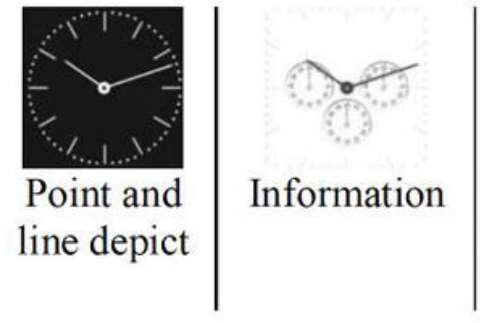

(b) surface
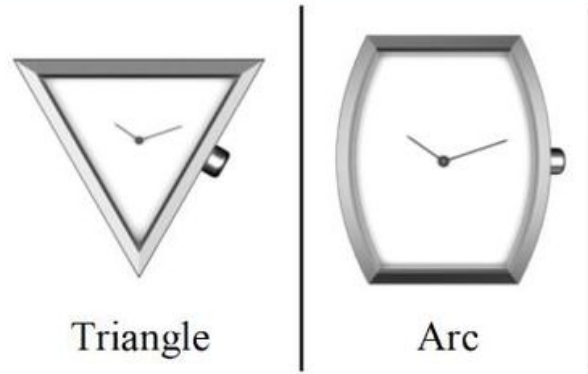

Arc
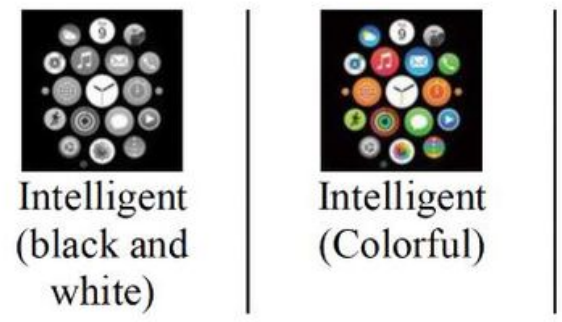

Figure 2

Basic types of watch frame and watch surface shape

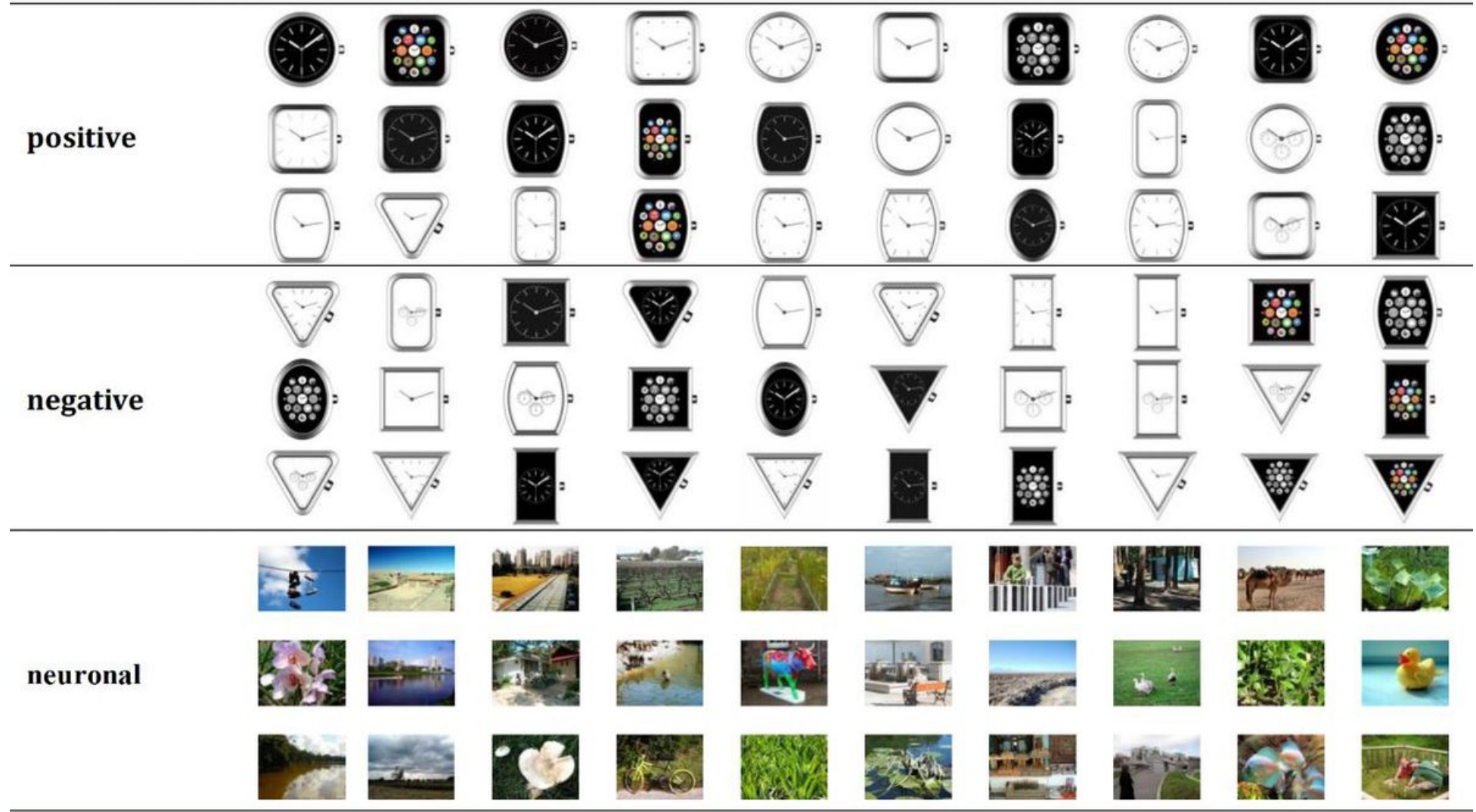

Figure 3

Positive, negative, and neutral samples 
Fixation point

ISI
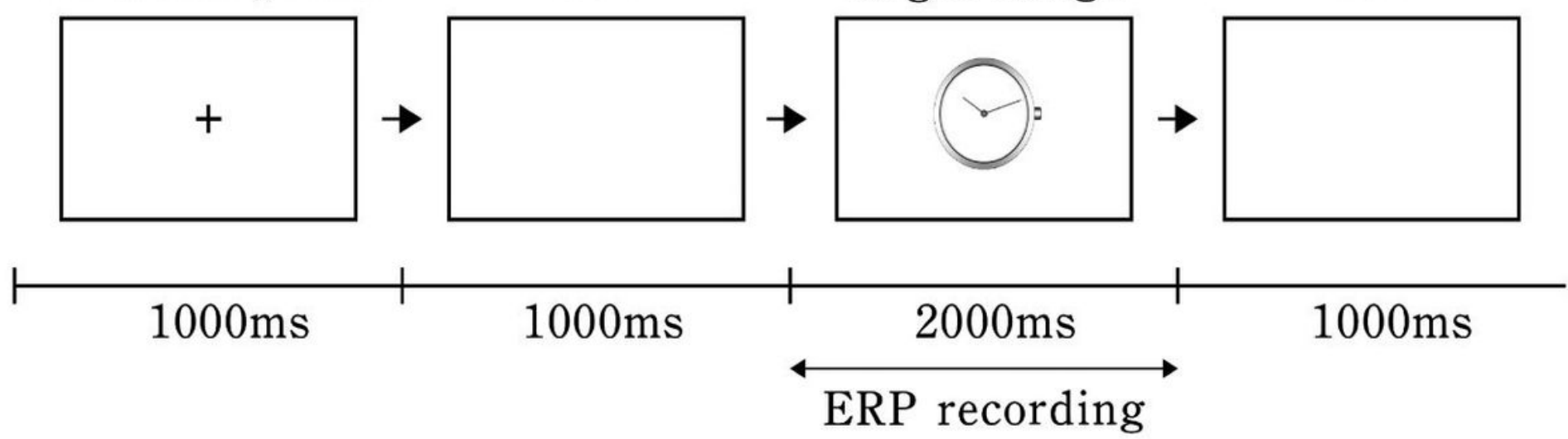

Figure 4

ERP testing procedure

F3

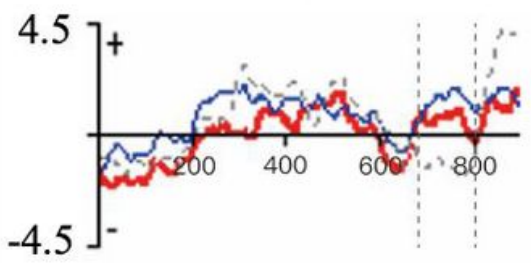

C3

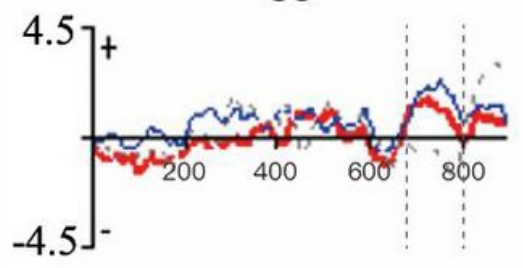

P3

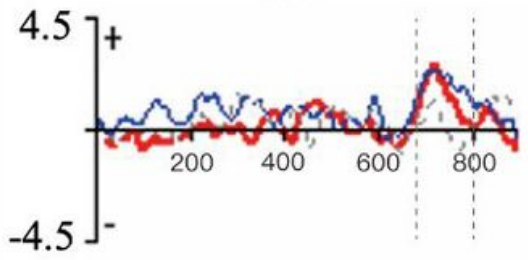

Fz

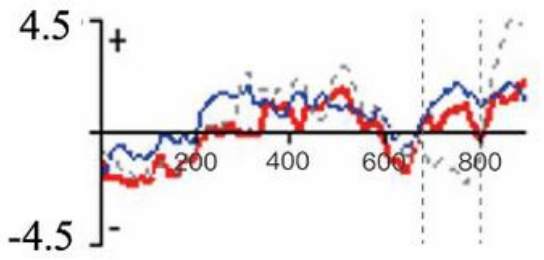

$\mathrm{Cz}$

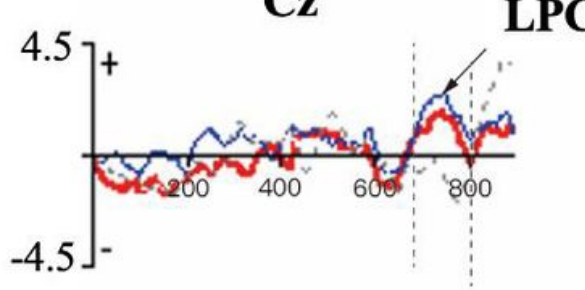

Pz

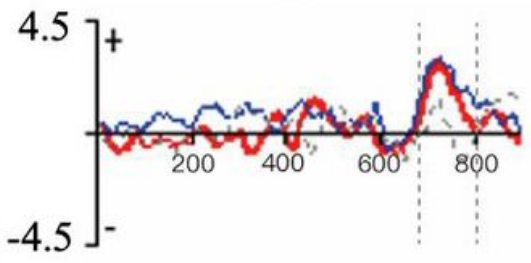

F4

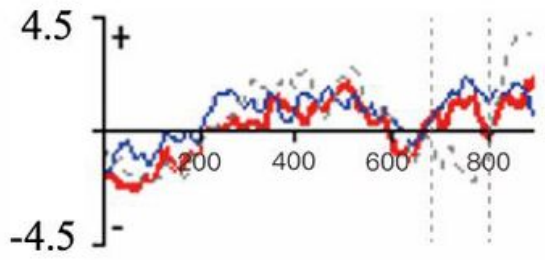

C4

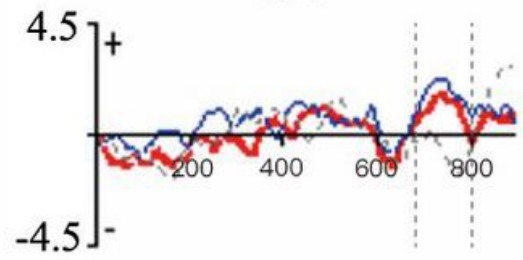

P4

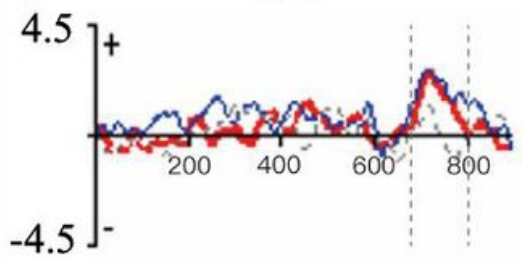

Positive

Negative

Neutral

Figure 5

ERP waveform: LPC position is at approximately $680 \mathrm{~ms}$ to $800 \mathrm{~ms}$

\section{Supplementary Files}

This is a list of supplementary files associated with this preprint. Click to download.

- renamedce5e7.doc 